\title{
Optimization of Subcritical Water Extraction of Polysaccharides from Inonotus Obliquus and their Antioxidant Activities
}

\author{
Xi Yuan ${ }^{1}$, Ling Li $^{1}$, Hongyi Sun ${ }^{1}$, Shuang Sun ${ }^{1} \&$ Zhenya Zhang ${ }^{1}$ \\ ${ }^{1}$ Graduate School of Life and Environmental Sciences, University of Tsukuba, Ibaraki, Japan \\ Correspondence: Zhenya Zhang, Graduate School of Life and Environmental Sciences, University of Tsukuba, \\ Ibaraki 305-8577, Japan. Tel: 81-29-853-4712. E-mail: zhang.zhenya.fu@u.tsukuba.ac.jp
}

Received: May 2, 2017

doi:10.5539/ijb.v9n3p38
Accepted: May 12, 2017

Online Published: May 22, 2017

\begin{abstract}
Subcritical water extraction (SWE) of Inonotus Obliquus polysaccharides (IOP) was investigated using response surface methodology (RSM) with a design by Box-Behnken design (BBD). Results showed that the optimum SWE conditions for IOP production were as follows: extraction temperature $194^{\circ} \mathrm{C}$, residence time $5.36 \mathrm{~min}$ and liquidsolid ratio $53 \mathrm{~mL} / \mathrm{g}$, yielding $168.80 \pm 0.59 \mathrm{mg} / \mathrm{g}$ of IOP, which was in close agreement with the values predicted by the mathematical model. FT-IR spectra of the polysaccharides extracted by SWE and hot water extraction (HWE) were compared as well. Moreover, in vitro antioxidant assays revealed that SWE-IOP exhibited stronger scavenging activity that HWE-IOP. This investigation suggests that polysaccharides of Inonotus Obliquus extracted by SWE could be further developed as a potential antioxidant resource for dietary supplements of functional food.
\end{abstract}

Keywords: subcritical water extraction, optimization, Inonotus Obliquus, polysaccharides, antioxidant activity

\section{Introduction}

Nowadays, the interest in natural antioxidants considered as functional ingredients for pharmaceuticals, functional foods, dietary supplements, animal feed, cosmetics and other products, is getting momentum due to not only the generalizability of their action in various redox systems but also consequently broad spectra of possible applications (Augustyniak et al., 2010). As one of the vital natural antioxidants, polysaccharides are an important class of polymeric carbohydrate molecules composed of long chains of monosaccharide units joined together by glycosidic linkages. Studies showed that polysaccharides from Inonotus obliquus possess a wide range of pharmacologic and health-promoting properties including immune enhancement (Kim et al., 2005; Wasser, 2002), anti-oxidation (Cui, Kim, \& Park, 2005), anti-diabetes (C. Wang, Chen, Pan, Gao, \& Chen, 2017), and anti-tumor (Yiyong Chen et al., 2010).

In recent decades, subcritical water extraction (SWE, also called hot-compressed water or hydrothermal extraction) has been applied in the isolation of valuable components, especially polysaccharides from plants. By definition, SWE refers to water at a temperature ranging from $100^{\circ} \mathrm{C}$ (the boiling point of water) to $374^{\circ} \mathrm{C}$ (the critical point of water) under sufficient pressures (1-22.1 MPa) that high enough to maintain its liquid state (Ramos, Kristenson, \& Brinkman, 2002). Specifically, the water polarity affected by dielectric constant decreases as the temperature increase, which makes it possible to selectively extract polar, bipolar, and nonpolar substances (Anekpankul, Goto, Sasaki, Pavasant, \& Shotipruk, 2007). Besides, ionization constant of the subcritical water substantially increases with temperature, catalyzing chemical reactions such as hydrolysis and degradation without any additional catalyst (Öztürk, Irmak, Hesenov, \& Erbatur, 2010). Additionally, water density, viscosity, diffusivity, electric conductance, and solvent ability are all changed (Chao, Ri-fu, \& Tai-qiu, 2013). Therefore, SWE has been attracted considerable attention due to its temperature-dependent selectivity, environmentally friendly nature, highefficiency, and low-cost, compared with the conventional methods (Chao et al., 2013).

Response surface methodology (RSM), as an effective statistical analysis technique, has been employed to optimize complex process parameters, including the extraction of polysaccharides, by evaluating interactions among various factors, as well as simultaneously estimating the effects of several process variables and their interactions on response variables (Maran, Manikandan, Thirugnanasambandham, Nivetha, \& Dinesh, 2013). BBD-based statistical modeling, as one of the several statistical designs belonging to RSM represents an independent quadratic design that does not contain an embedded factorial or fractional factorial design (Maran et 
al., 2013). It has been distinguished as a simplified design to cover three levels of experimental factors with less number of experiments (Zhao et al., 2011).

To the best of our knowledge, there is few literature investigated the Inonotus obliquus polysaccharides through subcritical water extraction. Hence, the objective of this chapter was to optimize the operational parameters (extraction temperature, residence time and liquid-solid ratio) of SWE to achieve the maximum yield of IOP by using RSM with a BBD design and their antioxidant activities were compared to with polysaccharides obtained by hot water extraction (HWE).

\section{Materials and Methods}

\subsection{Chemicals and Reagents}

Hydrogen peroxide, ascorbic acid, sodium hydroxide, sodium acetate trihydrate, chloride ferric, ferrous sulphate, dibasic sodium phosphate, sodium dihydrogen phosphate, sodium salicylate, ethanol, chloroform, n-butano, potassium persulphate, phenol, and D-glucose were purchased from Wako Pure Chemical (Osaka, Japan). 2,2'azino-bis (3-ethylbenzothiazoline-6-sulfonic acid) were purchased from Sigma-Aldrich, Inc. (Saint Louis, MO, USA). All the chemical reagents were of analytical grade.

\subsection{Preparation of I. obliquus}

In this study, I. obliquus was obtained from the same batch in the manufacturing process. Samples were dried at $60^{\circ} \mathrm{C}$ for $5 \mathrm{~h}$ to remove residual water and then ground in a high-speed disintegrator (IFM-800, IWATANI, JAPAN) to obtain a fine powder $(250 \mu \mathrm{m})$. Ground I. obliquus was refluxed twice with ethanol (volume fraction $85 \%)$ at $70^{\circ} \mathrm{C}$ in a water bath for $4 \mathrm{~h}$ to defat, deactivate enzymes and remove some interference materials (colored materials, oligosaccharides, and some small molecule materials). The ethanol mixture extract was centrifuged ( $3000 \mathrm{rpm}, 20$ $\mathrm{min}$ ). After removing supernatant, precipitation was vacuum dried at $50^{\circ} \mathrm{C}$ for $12 \mathrm{~h}$ and vacuum packed to reduce lipid oxidation.

\subsection{Subcritical Water Extraction (SWE) and Hot Water Extraction (HWE)}

The SWE was performed in a subcritical device (MMS-200, OMLABO, JAPAN) equipped with a temperature controller and a pressure gauge (Figure 1). Sample (1.0 g) was extracted with distilled water under the predesigned conditions. The extracts were centrifuged at $7500 \mathrm{rpm}$ for $20 \mathrm{~min}$ and filtrated $(0.45 \mu \mathrm{m}$, Millipore, USA) to collect the supernatant. The supernatant were concentrated by a rotary evaporator into a certain volume under reduced pressure at $60^{\circ} \mathrm{C}$, and then precipitated by the addition of absolute ethanol to a final concentration of $80 \%(\mathrm{v} / \mathrm{v})$ overnight at $4^{\circ} \mathrm{C}$. The precipitates were collected as crude IOP after centrifugation at $7500 \mathrm{rpm}$ for $15 \mathrm{~min}$, washed triple times using dehydrated ethanol. After being re-dissolved in ultrapure water, the aqueous solution was subjected to remove proteins by using Sevag reagent (chloroform and n-butanol in a 4:1 ratio), dialyzed with deionized water for $72 \mathrm{~h}$, concentrated under reduced pressure. Finally, the IOP product was collected after lyophilization. The obtained crude polysaccharides were re-dissolved in doubly distilled water for polysaccharides yield and antioxidant capacity determination. The polysaccharides content of crude IOP was determined based on the phenol-sulfuric acid method (D. Zhang, Li, Xiong, Jiang, \& Lai, 2013). The results were expressed as the polysaccharides content in per gram of dry soybean residue using the following equation:

$$
\text { OP yield }(\mathrm{mg} / \mathrm{g})=C \times N \times V / W
$$

where $C$ is the concentration of polysaccharides as calculated from the calibrated regression equation $(\mathrm{mg} / \mathrm{mL}) ; N$ is the dilution factor; $V$ is the total volume of extraction solution $(\mathrm{mL})$; and $W$ is the weight of the sample $(\mathrm{g})$.

For comparison, in hot water extraction, a $5.0 \mathrm{~g}$ Ground I. Obliquus was extracted using $150 \mathrm{~mL}$ of distilled water at $100^{\circ} \mathrm{C}$ for $2 \mathrm{~h}$.

\subsection{Single-Factor Experiment Design}

A series of single-factor experiments was conducted to identify the independent variables and investigate the preliminary BBD range of extraction factors including extraction temperature ranging from 160 to $200^{\circ} \mathrm{C}$, residence time ranging from 0 to $20 \mathrm{~min}$ and liquid-solid ratio ranging from 30 to $80 \mathrm{~mL} / \mathrm{g}$. The extraction yield of IOP was the dependent variable. Each experimental factor was determined while others were retained constant. Each experiment was performed in triplicate. 


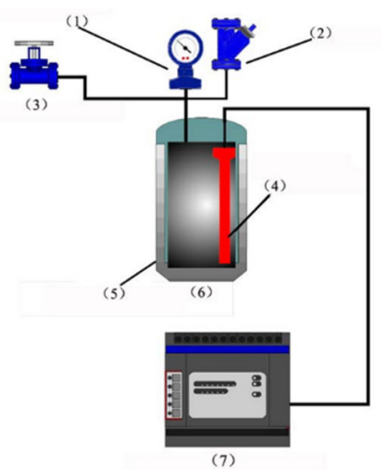

Figure 1. Experimental schematic diagram of subcritical water extraction. (1) Pressure gauge, (2) Safety head,

(3) Pressure release value, (4) Temperature sensor, (5) Insulation lagging, (6) SWE reactor, (7) Temperature controller and thermocouple

\subsection{Experimental Design of RSM}

On the basis of results of the former single-factor experiments, BBD with RSM was applied to optimize the extraction conditions of IOP. Three independent variables $\left(\mathrm{X}_{1}\right.$, extraction temperature; $\mathrm{X}_{2}$, residence time and $\mathrm{X}_{3}$ liquid-solid ratio) and their levels followed in the second stage have been shown in Table 1. For the statistical calculation, process factors are coded according to Eq. (2):

$$
x_{\mathrm{i}}=\left(X_{\mathrm{i}}-X_{0}\right) / \Delta X \quad \mathrm{i}=1,2,3
$$

where $x_{\mathrm{i}}$ is the coded value of the independent factor; $X_{\mathrm{i}}$ is the actual value of the independent variable, $X_{0}$ is the actual value of $X_{\mathrm{i}}$ at the central point, and $\Delta X$ is the step change value.

Table 1. Independent variables and their levels used in the response surface design (BBD)

\begin{tabular}{ccccc}
\hline \multirow{2}{*}{ Independent variables } & \multirow{2}{*}{ Symbol } & -1 & \multicolumn{3}{c}{ Levels } \\
\cline { 3 - 5 } & & 180 & 190 & 200 \\
\hline Temperature $\left({ }^{\circ} \mathrm{C}\right)$ & $X_{1}$ & 0 & 5 & 10 \\
Residence time $(\mathrm{min})$ & $X_{2}$ & 40 & 50 & 60 \\
Liquid-solid ratio $(\mathrm{mL} / \mathrm{g})$ & $X_{3}$ & & \\
\hline
\end{tabular}

All these runs were measured in a random order to maximize the effect of unexplained variability in the observed response due to extraneous factors and minimize the impact of non-controlled variables. Data from three repeated experiments were analyzed by multiple regressions to fit into the general form of a quadratic polynomial model as showed in the following Eq. (3),

$$
Y=\beta_{0}+\sum_{\mathrm{i}=1}^{3} \beta_{\mathrm{i}} \mathrm{x}_{\mathrm{i}}+\sum_{\mathrm{i}=1}^{3} \beta_{\mathrm{ii}} \mathrm{x}_{\mathrm{i}}^{2}+\sum_{\mathrm{i}=1}^{2} \sum_{\mathrm{j}=\mathrm{i}+1}^{3} \beta_{\mathrm{ij}} \mathrm{x}_{\mathrm{i}} \mathrm{x}_{\mathrm{j}}
$$

where $Y$ is the predicted response variable associated with each three levels combination (IOP yield), $B_{0}$ is the constant coefficient, $B_{i}$ is the liner coefficient, $B_{i i}$ is the quadratic coefficient, and $B_{i j}$ is the two-factor interaction coefficient. $X_{i}$ and $X_{j}$ are the levels of the independently coded variables $(i \neq j)$.

The experimental design, data analysis, and model building of the previous study were performed using DesignExpert software (8.0.5 Statease Inc., Minneapolis, USA). All trials were performed in triplicate.

\subsection{Fourier Transform Infrared Spectroscopy of IOP}

FT-IR was designed to identify the obtained IOP, which was carried out with the KBr-disk method (S. Li \& Shah, 2014) using a Jasco FTIR 3000 spectrometer (Jasco, Wakayama, Japan). The dried OP was mixed thoroughly with potassium bromide $(\mathrm{KBr})$ powder, ground and pressed into 1-mm pellet for spectrometric measurement at a frequency range of $400-4000 \mathrm{~cm}-1$. 
Table 2. Box-Behnken design matrix of the three variables (coded and uncoded units) and results for the extraction rate of IOP

\begin{tabular}{cccccc}
\hline \multirow{2}{*}{ Run } & $\begin{array}{c}\text { Temperature } \\
\left({ }^{\circ} \mathrm{C}\right)-X_{1}\end{array}$ & $\begin{array}{r}\text { Residence time } \\
(\mathrm{min})-X_{2}\end{array}$ & $\begin{array}{r}\text { Liquid-solid ratio } \\
(\mathrm{mL} / \mathrm{mg})-X_{3}\end{array}$ & \multicolumn{2}{c}{ Polysaccharide content $(\mathrm{mg} / \mathrm{g})$} \\
\hline 1 & $-1(180)$ & $-1(0)$ & $0(50)$ & 83.21 & 83.32 \\
2 & $1(200)$ & $-1(0)$ & $0(50)$ & 151.98 & 151.89 \\
3 & $-1(180)$ & $1(10)$ & $0(50)$ & 144.41 & 144.52 \\
4 & $1(200)$ & $1(10)$ & $0(50)$ & 132.72 & 132.62 \\
5 & $-1(180)$ & $0(5)$ & $-1(40)$ & 119.66 & 119.63 \\
6 & $1(200)$ & $0(5)$ & $-1(40)$ & 144.14 & 144.32 \\
7 & $-1(180)$ & $0(5)$ & $1(60)$ & 15.08 & 126.91 \\
8 & $1(200)$ & $0(5)$ & $-1(40)$ & 119.57 & 158.89 \\
9 & $0(190)$ & $-1(0)$ & $-1(40)$ & 138.09 & 119.49 \\
10 & $0(190)$ & $1(10)$ & $1(60)$ & 151.91 & 138.02 \\
11 & $0(190)$ & $-1(0)$ & $1(60)$ & 163.67 & 127.98 \\
12 & $0(190)$ & $1(10)$ & $0(50)$ & 164.36 & 151.38 \\
13 & $0(190)$ & $0(5)$ & $0(50)$ & 165.73 & 164.64 \\
14 & $0(190)$ & $0(5)$ & $0(50)$ & 165.05 & 164.64 \\
15 & $0(190)$ & $0(5)$ & $0(50)$ & 164.36 & 164.64 \\
16 & $0(190)$ & $0(5)$ & $0(50)$ & & 164.64 \\
17 & $0(190)$ & $0(5)$ & & 164.64 \\
\hline
\end{tabular}

\subsection{Evaluation of Antioxidant Capacity}

\subsubsection{DPPH Radical Scavenging Activity Assay}

DPPH radical scavenging activity of extractions was evaluated according to a literature procedure with slight modifications (Sun et al., 2013). Aliquots $(0.5 \mathrm{~mL})$ of various concentrations $(0.3125-10.00 \mathrm{mg} / \mathrm{mL})$ of solutions were mixed with $3 \mathrm{~mL}(25 \mu \mathrm{g} / \mathrm{mL})$ of a MeOH solution of DPPH and then were shaken vigorously and allowed to stand in the dark for $30 \mathrm{~min}$. The absorbance was measured with a spectrophotometer at $517 \mathrm{~nm}$ against a blank. A decrease of the DPPH solution absorbance indicated an increase in the DPPH radical scavenging activity. Ascorbic acid was invoked as positive controls. The DPPH radical scavenging activity was calculated according to the following equation:

$$
\text { Scavenging activity }(\%)=\left(1-\mathrm{A}_{1} / \mathrm{A}_{0}\right) \times 100 \%
$$

where $\mathrm{A}_{0}$ is the absorbance without samples and $\mathrm{A}_{1}$ the absorbance containing the samples.

\subsubsection{SOD-like Activity Assay}

The SOD-like activity of the extracts was measured by the SOD Assay Kit-WST according to the technical manual provided by Dojindo Molecular Technologies, Inc. Firstly, $20 \mu 1$ of the sample solution was added to blank 2 well and each sample, meanwhile, $20 \mu \mathrm{l}$ of double distilled water was added to each blank 1 and blank 3 well in a 96well plate. After that, $200 \mu \mathrm{l}$ of WST working solution was added to each well, mixed waiting for further processing. Then, $20 \mu \mathrm{l}$ of dilution buffer was added to each blank 2 and blank 3 well, and $20 \mu$ lof enzyme working solution was added to each sample and blank 1 well. The plate was incubated at $37^{\circ} \mathrm{C}$ for 20 min and the optical density (OD) was measured at $450 \mathrm{~nm}$ using a microplate reader ( Bio-Rad Model 550, USA ). SOD-like activity was calculated by the following equation:

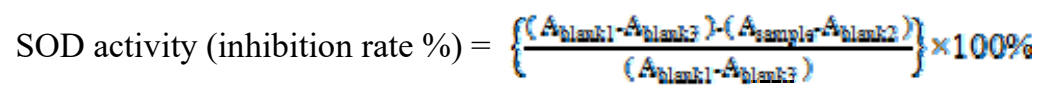

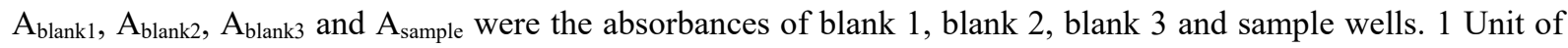
SOD activity was defined as the amount of enzyme having a 50\% inhibitory effect on WST-1.

$\mathrm{IC}_{50}$ value $(\mathrm{mg} / \mathrm{mL})$ was the effective concentration at which SOD activity was scavenged by $50 \%$ and was obtained by interpolation from a linear regression analysis. 


\subsubsection{Hydroxyl Radical Scavenging Activity Assay}

Hydroxyl free radicals generated from $\mathrm{FeSO}_{4}$ and $\mathrm{H}_{2} \mathrm{O}_{2}$ were detected by their ability to hydroxylate salicylate. The reaction mixture $(2.5 \mathrm{~mL})$ contained $0.5 \mathrm{~mL}$ of $\mathrm{FeSO}_{4}(1.5 \mathrm{mM}), 0.35 \mathrm{~mL}$ of $\mathrm{H}_{2} \mathrm{O}_{2}(6 \mathrm{mM}), 0.15 \mathrm{~mL}$ of sodium salicylate $(20 \mathrm{mM})$, and $1.0 \mathrm{~mL}$ of different concentrations of the IOP. Ascorbic acid was used as the positive control. The absorbance of the hydroxylated salicylate complex was measured at $562 \mathrm{~nm}$ after incubation at $37^{\circ} \mathrm{C}$ for $1 \mathrm{~h}$. The scavenging effect on hydroxyl free radicals was calculated as Eq. (6).

$$
\text { Scavenging activity }(\%)=\left[1-\left(\mathrm{A}_{1}-\mathrm{A}_{2}\right) / \mathrm{A}_{0}\right] \times 100 \%
$$

where $A_{1}$ is the absorbance of the sample or ascorbic acid, and $A 0$ is the absorbance of the solvent control, whereas $\mathrm{A}_{2}$ is the absorbance of the reagent blank without sodium salicylate.

\subsection{Statistical Analysis}

Analysis of the experimental design and data was performed using Design-Expert software of version 8.0.5 (StatEase Inc., Minneapolis, USA). All experimental results were expressed as means \pm SD of triplicate experiments. All analyses were performed using the Statistical Package for the Social Sciences (SPSS, 19.0). Statistically significant was assumed at $P<0.05$.

\section{Results and Discussion}

\subsection{Single Factor Experimental Analysis}

\subsubsection{Effect of Extraction Temperature on the Extraction Yield}

The extraction temperature is a crucial parameter affecting the extraction efficiency and selectivity (Ye \& Jiang, 2011). With an appropriate temperature, targets compounds tied on the sample matrices by means of physical adsorption and chemical interactions were released into extraction solvents (Qi et al., 2015) and even modify the characteristics of solvent like decreasing the viscosity and increasing the diffusion, which all make great contributions to the mass transportation of targeted ingredients. The effect of temperature $(160,170,180,190$ and $200^{\circ} \mathrm{C}$ ) on the IOP yield is illustrated in Figure $2 \mathrm{a}$ when the other factors, residence time and liquid-solid ratio, were fixed at $20 \mathrm{~min}$ and $80 \mathrm{~mL} / \mathrm{g}$, respectively. As outlined, as the temperature changed from 160 to $190^{\circ} \mathrm{C}$, the extraction efficiency increased rapidly and the polysaccharides yield reached a maximum of $132.62 \pm 2.63 \mathrm{mg} / \mathrm{g}$ at $190^{\circ} \mathrm{C}$. Upon further temperature increased, the polysaccharide yield decreased sharply, indicating that excessive temperature may lead to degradation and decomposition of polysaccharides induced by browning reaction, whose chemical products are not detected in a phenol-sulphuric assay and, then, decrease the concentration of IOP yield (Xu et al., 2016). In terms of extraction efficiency and energy consumption, an extraction temperature of $190^{\circ} \mathrm{C}$ was employed in subsequent extraction experiments.

\subsubsection{Effect of Residence Time on the Extraction Yield}

Extraction time is another important parameter influencing the extraction rate and quality of yielded compounds. It usually takes polysaccharides some time to contact the release medium, where solvent permeated into the dried materials so that they could be dissolved and diffused out subsequently from the materials (C.-p. Zhu, Zhai, Li, $\mathrm{Wu}, \& \mathrm{Li}, 2015)$. Apart from that, extraction time is crucial in minimizing energy and production cost, which is especially noticeable in the extraction process. Thus, considering economic efficiency and energy consumption, the effect of the extraction time on the yield of IOP was investigated and the extraction process was performed for different extraction time from 0 to 20 min when the other factors were as follows: liquid to solid ratio $80: 1 \mathrm{~mL} / \mathrm{g}$ and temperature $190^{\circ} \mathrm{C}$, respectively. As illustrated in Figure $2 \mathrm{~b}$, the IOP yield was positively correlated with an increased duration, and it increased up to a maximum amount of $151.09 \pm 2.77 \mathrm{mg} / \mathrm{g}$ in $5 \mathrm{~min}$, which meant a great number of IOP was released to exterior solvent in this early extraction stage. Thereafter, IOP began to continually decrease, which can be attributed to the degradation and hydrolysis of polysaccharides exposed to high temperature for a long extraction time, especially under subcritical water conditions. For this reason, the extraction time was controlled in the range of $5 \mathrm{~min}$.

\subsubsection{Effect of Liquid-Solid Ratio on the Extraction Yield}

In classical extraction methods, the solid-liquid ratio is recognized as one of the major parameters for affecting the effectiveness of the procedure and the quality of the extracts. Various liquid-solid ratio can directly impact the concentrations between the interior plant cells and the exterior solvent, significantly affecting the yield of the extracted polysaccharides (Yuzhen Chen, Zhao, Liu, \& Zuo, 2012). An inappropriate liquid-solid ratio may result in the incompleteness of polysaccharides or solvent waste. Therefore, different liquid-solid ratio including 30,40, $50,60,70$ and $80 \mathrm{~mL} / \mathrm{g}$ was tested while the other two extraction variables (extraction temperature and residence time) were set in the central points as follows: $190^{\circ} \mathrm{C}$ and $5 \mathrm{~min}$, respectively. As presented in Figure 2c, the 
extraction yield of IOP initially increased slightly with increasing the liquid to solid ratio and reached a maximum yield $(157.17 \pm 0.65 \mathrm{mg} / \mathrm{g}$ ) when the liquid-solid ratio was $50 \mathrm{~mL} / \mathrm{g}$. And then, as the liquid-solid ratio continued to increase, the yield tended to decrease. The reason of this is some certain liquid-solid ratio can promote diffusivity of the solvent into the cells and enhance the leaching-out rates of polysaccharides therefrom. However, an excess of solvent could consume cavitation energy from the extraction system and complicate extraction procedure, resulting in a lower IOP yield. Hence, to minimize electricity and time costs, a liquid-solid ratio of $50 \mathrm{~mL} / \mathrm{g}$ was selected to ensure the extraction yield.
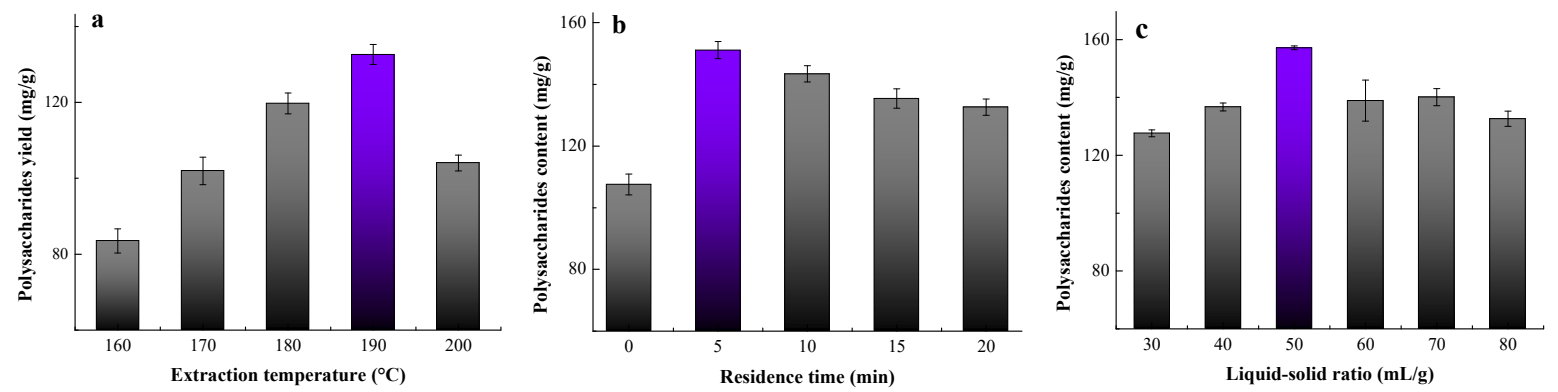

Figure 2. Effect of extraction temperature (a), residence time (b), and liquid-solid ratio (c) on the extraction yield of IOP. (a) $20 \mathrm{~min}$ of residence time and $80 \mathrm{~mL} / \mathrm{g}$ of liquid-solid ratio; (b) $190^{\circ} \mathrm{C}$ of temperature and $80 \mathrm{~mL} / \mathrm{g}$ of

liquid-solid ratio; (c) 5 min of residence time and $190^{\circ} \mathrm{C}$ of temperature. Values are means \pm S.D. $(n=3)$

\subsection{Box-Behnken Design (BBD) for Optimization of Extraction Parameters}

\subsubsection{Statistical Analysis and the Model Fitting}

Based on single factor experiments mentioned above and according to BBD design matrix, a number of 17 experimental runs (12 runs for various conditions and 5 center point runs for the measurement of the process stability and inherent variability) with three factors and three levels were performed to study the reciprocal influence of three independent variables (extraction temperature, residence time and liquid-solid ratio) on IOP extraction yield and establish the optimal SWE conditions. The variables of the actual and coded levels and the experimental results performed three times were represented in Table 1 and Table 2, respectively. As could be seen, the IOP yield ranged from 83.21 to $165.73 \mathrm{mg} / \mathrm{g}$. Using multiple regression analysis of the experimental data using Design Expert software version 8.0.5, the data in Table 2 were carried out. The fitted model for the IOP yield $(\mathrm{mg} / \mathrm{g})$ was correlated according to the following second-order polynomial equation:



Where $Y$ is the yield of polysaccharides, $X_{1}, X_{2}$, and $X_{3}$ are the coded variables for extraction temperature, residence time and liquid-solid ratio, respectively.

Analysis of variance (ANOVA) and F-test was employed to evaluate the significance and to analyze the adequacy and the goodness-of-fit of the response surface quadratic model (Table 3). The high quadratic regression model significance was identified by its high $\mathrm{F}$-value $(\mathrm{F}=2408.99)$ and low $\mathrm{P}$-value $(\mathrm{P}<0.0001)$. The goodness-of-fit can be demonstrated by the determination coefficient $\left(\mathrm{R}^{2}\right)$, adjusted determination coefficient $\left(\mathrm{R}_{\mathrm{adj}}{ }^{2}\right)$ and coefficient of variance (C.V.) (L. Zhang \& Wang, 2017). $\mathrm{R}^{2}$ offers the proportion of the total variation in the response predicted by the model and indicates the ratio of sum of squares because of regression to the total sum of squares (Y. Zhang et al., 2016). $\mathrm{R}^{2}$ coefficient high closed to unity indicates a satisfactory adjustment of the quadratic model to the experiment statistics (Bezerra, Santelli, Oliveira, Villar, \& Escaleira, 2008). In this study, the determination coefficient $\left(\mathrm{R}^{2}\right)$ was 0.9997 , implying that $99.97 \%$ of the variations could be interpreted by the fitted model. Besides, a high degree of correlation between the observed and predicted values was confirmed since the adjusted determination coefficient $\left(\mathrm{R}_{\mathrm{adj}}{ }^{2}=0.9993\right)$ for the model had no obvious difference with $\mathrm{R}^{2}$. Moreover, a low coefficient of variation $(\mathrm{C} . \mathrm{V} .=1.07)$ indicated that the degree of precision and reliability of experimental values of the regression model was highly significant. The P-value was used as a tool to not only reveal the significance of each coefficient but also explain the interaction pattern of independent variables (Xu et al., 2016). The smaller the value of $\mathrm{P}$ with respect to 0.05 , the more significant the corresponding coefficient.

As all the regression coefficients listed in Table 3, it could be concluded that all the liner coefficient, the quadratic term coefficients, and the cross product coefficients with small $\mathrm{P}$-value $(\mathrm{P}<0.05)$ were significant for IOP 
extraction. This finding manifested that all the independent parameters analyzed in this study were important factors affecting the yield of extracted IOP. In addition, the significance of the model was also judged by a lackof-fit test, meaning the failure of the model to represent the data in the experimental domain at points that are not included in the regression (Ghafari, Aziz, Isa, \& Zinatizadeh, 2009). The ANOVA showed that lack of fit (F-value $=0.070$ and $\mathrm{P}$-value $=0.9728$ ) was not significantly relative to the pure error, implying that it was not significant and just a $2.72 \%$ chance could occur due to noise. Consequently, it was determined that proposed mathematical model and extraction parameters could be used to predict the yield of IOP under any combination of the values of different variables under SWE conditions.

Table 3. Analysis of variance (ANOVA) of the response surface quadratic model for the effects of extraction temperature $\left(\mathrm{X}_{1}\right)$, residence time $\left(\mathrm{X}_{2}\right)$ and liquid-solid ratio $\left(\mathrm{X}_{3}\right)$ on the extraction.

\begin{tabular}{|c|c|c|c|c|c|c|}
\hline Source & Sum of Squares & Df & Mean Square & F-value & P-value & Significant \\
\hline Model & 8019.19 & 9 & 891.02 & 2408.99 & $<0.0001$ & $* * *$ \\
\hline$X_{1}$ & 1605.59 & 1 & 1605.59 & 4340.93 & $<0.0001$ & $* * *$ \\
\hline$X_{2}$ & 878.95 & 1 & 878.95 & 2376.36 & $<0.0001$ & $* * *$ \\
\hline$X_{3}$ & 238.63 & 1 & 238.63 & 645.17 & $<0.0001$ & $* * *$ \\
\hline$X_{1} X_{2}$ & 1618.54 & 1 & 1618.54 & 4375.92 & $<0.0001$ & $* * *$ \\
\hline$X_{1} X_{3}$ & 13.29 & 1 & 13.29 & 35.92 & 0.0005 & $* * *$ \\
\hline$X_{2} X_{3}$ & 5.90 & 1 & 5.90 & 15.96 & 0.0052 & $* *$ \\
\hline$X_{1}^{2}$ & 1169.43 & 1 & 1169.43 & 3161.70 & $<0.0001$ & $* * *$ \\
\hline$X_{2}^{2}$ & 1665.12 & 1 & 1665.12 & 4501.85 & $<0.0001$ & $* * *$ \\
\hline$X_{3}^{2}$ & 467.17 & 1 & 467.17 & 1263.06 & $<0.0001$ & $* * *$ \\
\hline Residual & 0.22 & 7 & 0.03 & & & \\
\hline Lack of Fit & 0.13 & 3 & 0.043 & 0.070 & 0.9728 & $*$ \\
\hline Pure Error & 0.06 & 4 & 0.01 & & & \\
\hline Cor Total & 69.23 & 16 & & & & \\
\hline SD & 1.78 & & & & & \\
\hline Mean & 166.76 & & & & & \\
\hline C.V. (\%) & 1.07 & & & & & \\
\hline Press & 267.87 & & & & & \\
\hline$R^{2}$ & 0.9997 & & & & & \\
\hline Adj. $R^{2}$ & 0.9993 & & & & & \\
\hline Pred. $R^{2}$ & 0.9993 & & & & & \\
\hline Adequate precision & 43.0765 & & & & & \\
\hline
\end{tabular}

\footnotetext{
**Significant, $\mathrm{p}<0.05$

$* * *$ Highly significant, $\mathrm{p}<0.001$

*Non-significant, $\mathrm{p}>0.05$
}

\subsubsection{Response Surface Plot}

To represent a visual interpretation of the interactions between the independent and dependent variables, threedimensional response surface and two-dimensional (2D) contour plots (Figure 3) were achieved using DesignExpert software. Generally, 3D response surface plot can display the mutual influences of independent variables on the response variable and further assistance in finding the maximum, minimum and saddle points of the responses (Matos et al., 2015). For 2D response contour plots, not only do 2D response contour plots interpret the reciprocal interactions between independent variables, also reflect the significance of reciprocal interactions between the variables (Guo, Zou, \& Sun, 2010).

The three-dimensional response surface (Figure 3a) and contour plots (Figure 3b) illustrated the effects of extraction temperature as well as residence time on the yield of IOP at a fixed liquid-solid ratio of $50 \mathrm{~mL} / \mathrm{g}$. The IOP yield increased significantly as extraction temperature together with residence time increased in the range of $180.00^{\circ} \mathrm{C}-193.98^{\circ} \mathrm{C}$ and $0-5.36 \mathrm{~min}$, respectively. However, when these two parameters beyond the peak points, the yield decreased gradually, which probably due to excessive extraction time and temperature could lead to the hydrolyzation or degradation of polysaccharides. According to the elliptical shape of the contour plot, the 
relationships between extraction temperature and residence time were significant. Figure $3 \mathrm{c}$ and Figure $3 \mathrm{~d}$ showed the effects of extraction temperature and liquid-solid ratio on IOP yield when residence time was fixed at a zero level. A maximum IOP was obtained at $193.98^{\circ} \mathrm{C}$ with a liquid-solid ratio of $52.98 \mathrm{mg} / \mathrm{L}$. As shown in Figure $3 \mathrm{e}$ and Figure 3f, the IOP yield with varying residence time and liquid-solid ratio at a fixed ratio of extraction temperature ( 0 level) had been evaluated. The elliptical shape of the 2-D contour plot indicated that the mutual interaction between residence time and liquid-solid ratio was significant.
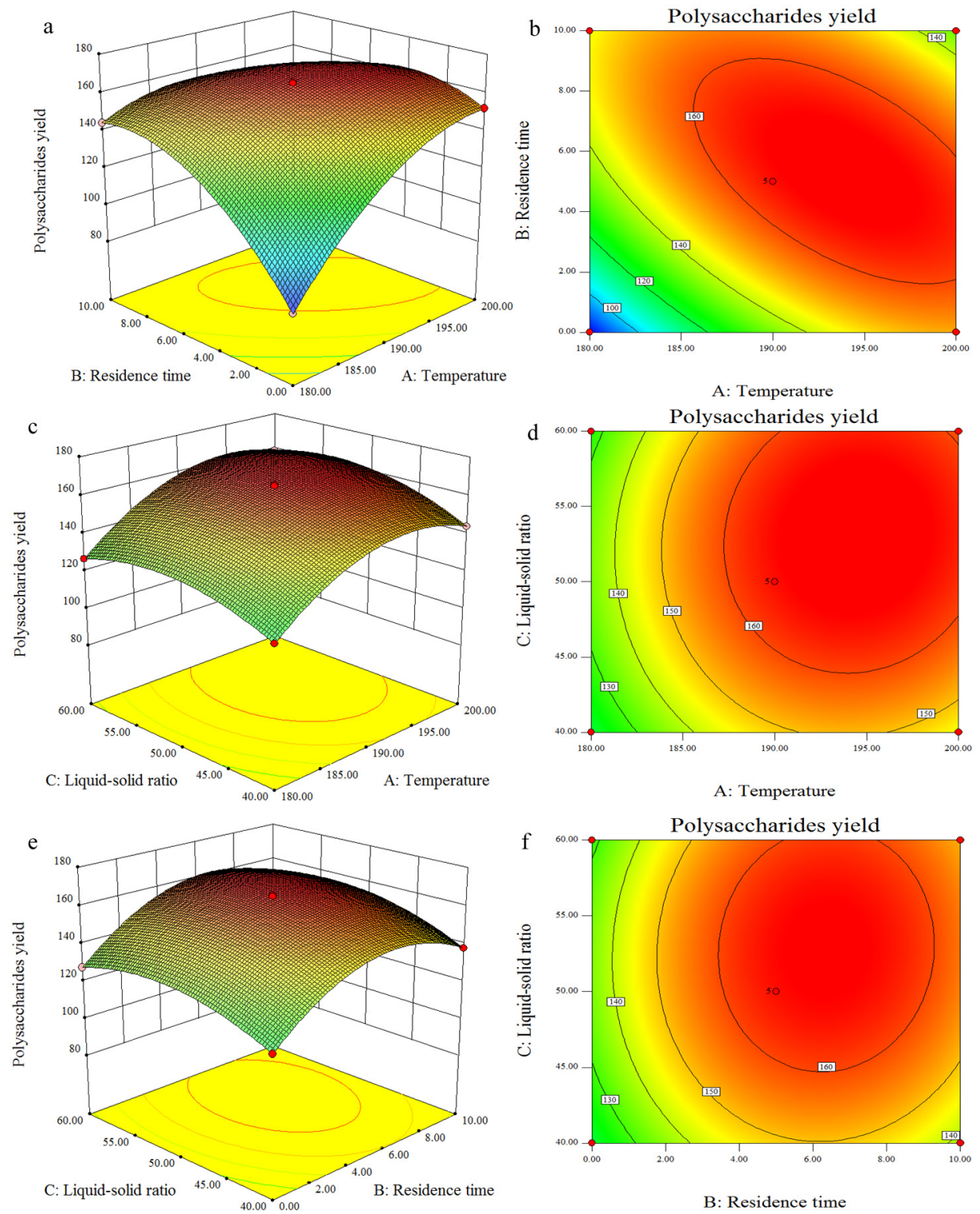

Figure 3. Response surface plots (a, c, and e) and contours plots (b, d, and f) for the effects of extraction temperature $\left(\mathrm{X}_{1}\right)$, residence time $\left(\mathrm{X}_{2}\right)$ and liquid-solid ratio $\left(\mathrm{X}_{3}\right)$ on the yield of IOP

\subsubsection{Optimization of Extraction Parameters and Validation of the Model}

The optimal values of independent variables and response variable for the proposed extraction were analyzed by Design-Expert software and recommended as follows: extraction temperature of $193.98^{\circ} \mathrm{C}$, residence time of 5.36 $\mathrm{min}$, and liquid-solid ratio of $52.98 \mathrm{~mL} / \mathrm{g}$ and the predicted value for IOP yield was $168.65 \mathrm{mg} / \mathrm{g}$. To validate the adequacy of the model equations, a verification experiment should be tested using the estimated optimal conditions However, considering feasible function of the apparatus, the parameters were modified slightly in the verification experiment as follows: extraction temperature of $194^{\circ} \mathrm{C}$, residence time of $5.36 \mathrm{~min}$, and liquid-solid ratio of 53 $\mathrm{mL} / \mathrm{g}$. Under these extraction conditions, triplicate confirmatory experiments were carried out and the average 
extraction yield of IOP was $168.80 \pm 0.59 \mathrm{mg} / \mathrm{g}$, which agreed closely with the predicted value. A good correlation between predicted and experimental values revealed that the regression model was accurate and adequate for the extraction of IOP by SWE method. Therefore, the model was suitable for the optimization of SWE extraction procedure for IOP.

\subsection{FT-IR Spectroscopy of IOP}

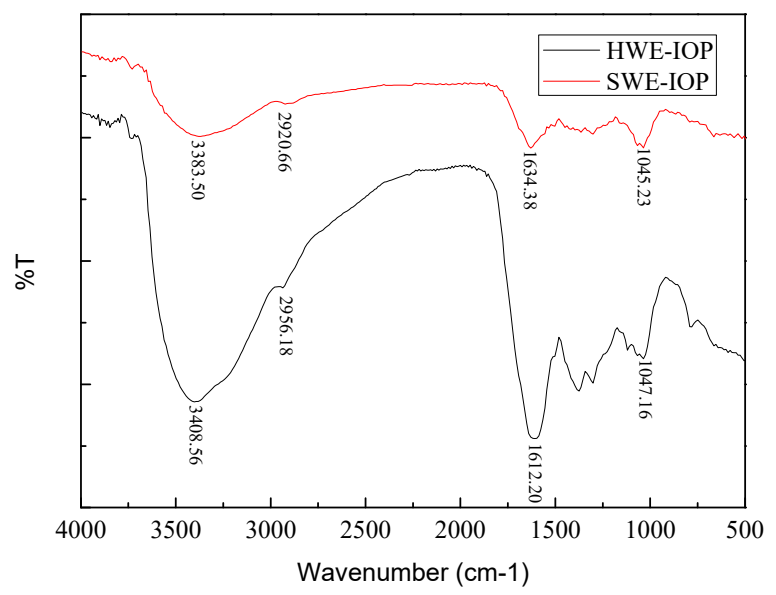

Figure 4. FT-IR spectrum of the polysaccharides extracted from Inonotus obliquus by using SWE (SWE-IOP) and HWE (HWE-IOP)

FT-IR spectroscopy is a practical technique for identification of characteristic organic groups and exhibition of structural features in polysaccharides (W. Chen et al., 2014). As shown in Figure 4, the FT-IR spectra of two polysaccharides (the black line for hot water extraction; the red line for subcritical water extraction) were almost same. Given the fact that the signals within the range of $3600-3300 \mathrm{~cm}^{-1}, 3000-2800 \mathrm{~cm}^{-1}$, and $1100-1000 \mathrm{~cm}^{-}$ ${ }^{1}$ are the characteristic absorption peaks of polysaccharides (C. Li, Fu, Luo, \& Huang, 2013), both HWE-IOP and SWE-IOP spectra could fit the typical pattern of polysaccharides well, indicating that the main structure of polysaccharides was not destroyed under subcritical water conditions. A strong and broad peak at approximately $3400 \mathrm{~cm}^{-1}$ (HWE-IOP: $3408.56 \mathrm{~cm}^{-1}$; SWE-IOP: $3383.50 \mathrm{~cm}^{-1}$ ) corresponded to a characteristic hydrogen bond O-H stretching vibration (Cheng et al., 2013). The absorption peak at around $2940 \mathrm{~cm}^{-1}$ (HWE-IOP: $2956.18 \mathrm{~cm}^{-}$ 1; SWE-IOP: $2920.66 \mathrm{~cm}^{-1}$ ) assigned to the $\mathrm{C}-\mathrm{H}$ asymmetric stretching vibration including $\mathrm{CH}-, \mathrm{CH}_{2}-$ and $\mathrm{CH}_{3}-$ (R. Wang, Chen, Jia, Tang, \& Ma, 2012). The bands at approximately $1630 \mathrm{~cm}^{-1}$ (HWE-IOP: $1612.20 \mathrm{~cm}^{-1}$; SWEIOP: $1634.38 \mathrm{~cm}^{-1}$ ) suggested the presence of the stretching vibration of $\mathrm{C}=\mathrm{O}$ or $\mathrm{C}=\mathrm{C}$ group in structure (Shi, Zhang, \& Yang, 2013). A range from $1000 \mathrm{~cm}^{-1}$ to $1200 \mathrm{~cm}^{-1}$ of extensive absorption bands indicated the stretching vibrations of C-O-H side groups, and C-O-C glycosidic band vibrations were observed in the spectra (Kacurakova, Capek, Sasinkova, Wellner, \& Ebringerova, 2000). The main absorptions of C-O stretching (HWE-IOP: 1047.16 $\mathrm{cm}^{-1}$; SWE-IOP: $1045.23 \mathrm{~cm}^{-1}$ ) showed that the characteristics of sugar structures were pyranose configuration (Y. Zhu et al., 2014). Overall, these results showed that polysaccharides extracted by HWE and SWE exhibited all of the typical absorption peaks of a polysaccharide.

\subsection{Antioxidant Activity}

\subsubsection{DPPH Radical Scavenging Activity}

DPPH assay has been widely used as a substrate to evaluate the antioxidant activity of samples, including natural polysaccharides (Yuan, Zhang, Fan, \& Yang, 2008). The scavenging activities of polysaccharides extracted by SWE and HWE against the DPPH radicals were shown in Figure 5A. Ascorbic acid was as the positive control to verify the validity and authenticity of the assay. In this study, ascorbic acid showed DPPH radical-scavenging activity of $97.80 \pm 0.23 \%$ at the initial concentration of $0.3125 \mathrm{mg} / \mathrm{mL}$, exhibiting excellent scavenging ability on DPPH radicals. And altered concentrations of all the SWE-extracts $(0.3125$, $0.625,1.25,2.5$, and $5 \mathrm{mg} / \mathrm{mL}$ ) showed DPPH scavenging activities in a dose-dependent manner. As shown, both IOP samples exhibited DPPH radical scavenging activities at a concentration range of $0.3125-5 \mathrm{mg} / \mathrm{mL}$. Specifically, when the sample concentration ranging from $0.3125-5 \mathrm{mg} / \mathrm{mL}$, the scavenging activity of SWE-IOP increased from $20.21 \%$ to $90.66 \%$ whereas the scavenging activity of HWE-IOP grew $13.57 \%$ to 
$75.78 \%$. The half inhibition concentration ( IC $\left._{50}\right)$ increased in the order of SWE-IOP $(0.86 \mathrm{mg} / \mathrm{mL})$ and HWEIOP $(1.78 \mathrm{mg} / \mathrm{mL})$, which indicated that the thermal processing condition for samples processed under subcritical water conditions significantly improved the scavenging ability to DPPH radicals. Moreover, these findings implied that IOP can donate an electron or hydrogen atom to scavenge DPPH radical.



Figure 5. Antioxidant activities of SWE-IOP, HWE-IOP, and ascorbic acid: (A) DPPH radicals scavenging activity, (B) SOD-like activity and (C) hydroxyl radicals scavenging activity. Values are means \pm S.D. $(n=3)$

\subsubsection{SOD-like Activity}

Superoxide dismutases (SODs), as metalloenzymes catalyzing the dismutation of superoxide anion to oxygen and hydrogen peroxide, ubiquitously exist in eukaryotes and prokaryotes (Liou \& Storz, 2010). SOD-like is recognized as a non-enzyme-small molecule super antioxidant that has a similar antioxidant function with SOD (Yang, Wu, Liu, Chai, \& Tseng, 2016). Hence, SOD-like activity assay is widely used to determine radical scavenging activity due to its ability to inhibit the auto-oxidation of pyrogallol. As showed in Figure 5B, at the initiate concentration of $0.3125 \mathrm{mg} / \mathrm{mL}$, the activity of SWE-IOP $(3.10 \pm 2.49 \%)$ was almost as twice as that of HWE-IOP $(1.58 \pm$ $0.44 \%$ ). With the increase of concentrations, SOD-like activity of both fractions increased dramatically, suggesting that IOP extracted by these two methods were sensitive to the expression of SOD-like. There was no difference between two kinds of IOP (SWE-IOP, 99.54 $\pm 0.16 \%$; HWE-IOP, $99.53 \pm 0.82 \%$ ) and ascorbic acid (99.14 \pm $0.42 \%$ ), indicating that IOP may have potential effects on human cells. Moreover, SOD-like activities were in a dose-dependent manner. As shown in Table 4, the $\mathrm{IC}_{50}$ values of SWE-IOP and HWE-IOP were $0.039 \mathrm{mg} / \mathrm{mL}$ and $0.077 \mathrm{mg} / \mathrm{mL}$, respectively.

\subsubsection{Hydroxyl Radical Scavenging Activity}

Hydroxyl radical, a detrimental oxidant, can react with bio-macromolecules functioning in living cells and induce damage to virtually all types of biomolecules, such as lipids, proteins, carbohydrates, and DNA. The hydroxyl radicals scavenging abilities of SWE-IOP and HWE-IOP are illustrated in Figure 5C. The results showed that IOP possessed a dose-dependent activity within the concentration of 0.3125 to $5 \mathrm{mg} / \mathrm{mL}$. It can be easily observed that both kinds of IOP had lower scavenging abilities than ascorbic acid at all tested concentrations. However, when the concentration was $0.3125 \mathrm{mg} / \mathrm{mL}$, SWE-IOP exhibited stronger scavenging activity even than that of ascorbic acid. As for SWE-IOP, the scavenging activity increased significantly from $57.82 \%$ to $91.41 \%$ at a concentration ranging from 0.3125 to $5 \mathrm{mg} / \mathrm{mL}$. Compared with the results of SWE-IOP, HWE-IOP has a lower inhibition ability, which increased from $32.08 \%$ to $85.48 \%$ with the increase of sample concentration ranging from 0.3125 to 5 
$\mathrm{mg} / \mathrm{mL}$. In addition, the $\mathrm{IC}_{50}$ values of SWE-IOP and HWE-IOP were $0.13 \mathrm{mg} / \mathrm{mL}$ and $0.41 \mathrm{mg} / \mathrm{mL}$, respectively (Table 4). The difference of scavenging activities between SWE-IOP and HWE-IOP may be attributed to the former research that a relatively elevated temperature exposure may exert an influence on bioactivity via modifying the molecular weight of polysaccharides (M. Zhang, Zhang, Cheung, \& Ooi, 2004). There are two possible ways for polysaccharides eliminating radicals: polysaccharides supply the hydrogen to combine with radicals so that the radical chain reaction can be terminated; polysaccharides themselves integrate with radical ions directly. But up till now, the exact mechanism underlying the free-radical scavenging activity exerted by polysaccharides is still not fully understood. Consequently, Inonotus Obliquus polysaccharides obtained by hot water extraction showed lower DPPH radical scavenging activities than that achieved by subcritical water extraction, suggesting that elevated temperature might appropriately degrade the high-molecular-weight polysaccharides and enhance their antioxidant activities.

Table 4. Comparison of IOP obtained by HWE and SWE.

\begin{tabular}{|c|c|c|c|c|c|c|c|}
\hline \multirow[b]{2}{*}{ Method } & \multicolumn{3}{|c|}{ Extraction conditions } & \multirow{2}{*}{$\begin{array}{l}\text { Extraction yield } \\
\qquad(\mathrm{mg} / \mathrm{g})\end{array}$} & \multicolumn{3}{|c|}{ Antioxidant assay $\left(\mathrm{IC}_{50}, \mathrm{mg} / \mathrm{mL}\right)$} \\
\hline & Temperature $\left({ }^{\circ} \mathrm{C}\right)$ & $\begin{array}{l}\text { Residence time } \\
\text { (min) }\end{array}$ & $\begin{array}{l}\text { Liquid-solid ratio } \\
(\mathrm{mL} / \mathrm{g})\end{array}$ & & $\mathrm{DPPH}$ & SOD-like & Hydroxyl \\
\hline HWE & 100 & 120 & 30 & $30.71 \pm 0.43$ & 1.780 & 0.077 & 0.413 \\
\hline SWE & 194 & 5.36 & 53 & $168.80 \pm 0.59$ & 0.859 & 0.039 & 0.129 \\
\hline
\end{tabular}

\section{Conclusion}

In this study, the conditions under subcritical water extraction for obtaining polysaccharides from I. Obliquus were optimized by response surface methodology with a Box-Behnken design. Based on the prediction test and adjustment of the actual procedure, the optimal conditions were as follows: extraction temperature of $194^{\circ} \mathrm{C}$, residence time of $5.36 \mathrm{~min}$, and liquid-solid ratio of $53 \mathrm{~mL} / \mathrm{g}$. Under these conditions, the experimental yield $(168.80 \pm 0.59 \mathrm{mg} / \mathrm{g})$ agreed closely with the predicted yield. Moreover, the extraction yields as well as antioxidant activity were investigated. SWE-IOP had stronger antioxidant activities with a higher extraction yield, compared to those polysaccharides extracted by hot water extraction. This study shows the possibility of extracting polysaccharides from I. Obliquus by using subcritical water extraction. Certainly, further studies on the precise chemical structures and biological functions of IOP are currently in progress.

\section{References}

Anekpankul, T., Goto, M., Sasaki, M., Pavasant, P., \& Shotipruk, A. (2007). Extraction of anti-cancer damnacanthal from roots of Morinda citrifolia by subcritical water. Separation and Purification Technology, 55(3), 343-349. https://doi.org/10.1016/j.seppur.2007.01.004

Augustyniak, A., Bartosz, G., Čipak, A., Duburs, G., Horáková, L. U., Łuczaj, W., . . Skrzydlewska, E. (2010). Natural and synthetic antioxidants: an updated overview. Free Radical Research, 44(10), 1216-1262. http://dx.doi.org/10.3109/10715762.2010.508495

Bezerra, M. A., Santelli, R. E., Oliveira, E. P., Villar, L. S., \& Escaleira, L. A. (2008). Response surface methodology (RSM) as a tool for optimization in analytical chemistry. Talanta, 76(5), 965-977. https://doi.org/10.1016/j.talanta.2008.05.019

Chao, Z., Ri-fu, Y., \& Tai-qiu, Q. (2013). Ultrasound-enhanced subcritical water extraction of polysaccharides from Lycium barbarum L. Separation and Purification Technology, 120, 141-147. https://doi.org/10.1016/ j.seppur.2013.09.044

Chen, W., Chen, J., Wu, H., Gou, Y., Hu, F., Liu, L., . . Zhang, P. (2014). Optimization of selenylation conditions for a pectic polysaccharide and its structural characteristic. International Journal of Biological Macromolecules, 69, 244-251. https://doi.org/10.1016/j.ijbiomac.2014.05.046

Chen, Y., Gu, X., Huang, S.-q., Li, J., Wang, X., \& Tang, J. (2010). Optimization of ultrasonic/microwave assisted extraction (UMAE) of polysaccharides from Inonotus obliquus and evaluation of its anti-tumor activities. International Journal of Biological Macromolecules, 46(4), 429-435. https://doi.org/10.1016/j.ijbiomac. 2010.02.003 
Chen, Y., Zhao, L., Liu, B., \& Zuo, S. (2012). Application of response surface methodology to optimize microwave-assisted extraction of polysaccharide from tremella. Physics Procedia, 24, 429-433. https://doi.org/10.1016/j.phpro.2012.02.063

Cheng, H., Feng, S., Jia, X., Li, Q., Zhou, Y., \& Ding, C. (2013). Structural characterization and antioxidant activities of polysaccharides extracted from Epimedium acuminatum. Carbohydrate Polymers, 92(1), 63-68. https://doi.org/10.1016/j.carbpol.2012.09.051

Cui, Y., Kim, D.-S., \& Park, K.-C. (2005). Antioxidant effect of Inonotus obliquus. Journal of Ethnopharmacology, 96(1), 79-85. https://doi.org/10.1016/j.jep.2004.08.037

Ghafari, S., Aziz, H. A., Isa, M. H., \& Zinatizadeh, A. A. (2009). Application of response surface methodology (RSM) to optimize coagulation-flocculation treatment of leachate using poly-aluminum chloride (PAC) and alum. Journal of Hazardous Materials, 163(2), 650-656. https://doi.org/10.1016/j.jhazmat.2008.07.090

Guo, X., Zou, X., \& Sun, M. (2010). Optimization of extraction process by response surface methodology and preliminary characterization of polysaccharides from Phellinus igniarius. Carbohydrate Polymers, 80(2), 344-349. https://doi.org/10.1016/j.carbpol.2009.11.028

Kacurakova, M., Capek, P., Sasinkova, V., Wellner, N., \& Ebringerova, A. (2000). FT-IR study of plant cell wall model compounds: pectic polysaccharides and hemicelluloses. Carbohydrate Polymers, 43(2), 195-203. https://doi.org/10.1016/S0144-8617(00)00151-X

Kim, Y. O., Han, S. B., Lee, H. W., Ahn, H. J., Yoon, Y. D., Jung, J. K., . . Shin, C. S. (2005). Immuno-stimulating effect of the endo-polysaccharide produced by submerged culture of Inonotus obliquus. Life Sciences, 77(19), 2438-2456. https://doi.org/10.1016/j.1fs.2005.02.023

Li, C., Fu, X., Luo, F., \& Huang, Q. (2013). Effects of maltose on stability and rheological properties of orange oil-in-water emulsion formed by OSA modified starch. Food Hydrocolloids, 32(1), 79-86. https://doi.org/10.1016/j.foodhyd.2012.12.004

Li, S., \& Shah, N. P. (2014). Antioxidant and antibacterial activities of sulphated polysaccharides from Pleurotus eryngii and Streptococcus thermophilus ASCC 1275. Food Chemistry, 165, 262-270. https://doi.org/10.1016/j.foodchem.2014.05.110

Liou, G.-Y., \& Storz, P. (2010). Reactive oxygen species in cancer. Free Radical Research, 44(5), 479-496. http://dx.doi.org/10.3109/10715761003667554

Maran, J. P., Manikandan, S., Thirugnanasambandham, K., Nivetha, C. V., \& Dinesh, R. (2013). Box-Behnken design based statistical modeling for ultrasound-assisted extraction of corn silk polysaccharide. Carbohydrate Polymers, 92(1), 604-611. https://doi.org/10.1016/j.carbpol.2012.09.020

Matos, Â. P., Ferreira, W. B., de Oliveira Torres, R. C., Morioka, L. R. I., Canella, M. H. M., Rotta, J., . . Sant'Anna, E. S. (2015). Optimization of biomass production of Chlorella vulgaris grown in desalination concentrate. Journal of Applied Phycology, 27(4), 1473-1483. https://doi.org/10.1007/s10811-014-0451-y

Öztürk, İ., Irmak, S., Hesenov, A., \& Erbatur, O. (2010). Hydrolysis of kenaf (Hibiscus cannabinus L.) stems by catalytical thermal treatment in subcritical water. Biomass and Bioenergy, 34(11), 1578-1585. https://doi.org/10.1016/j.biombioe.2010.06.005

Qi, X.-L., Peng, X., Huang, Y.-Y., Li, L., Wei, Z.-F., Zu, Y.-G., \& Fu, Y.-J. (2015). Green and efficient extraction of bioactive flavonoids from Equisetum palustre $L$. by deep eutectic solvents-based negative pressure cavitation method combined with macroporous resin enrichment. Industrial Crops and Products, 70, 142148. https://doi.org/10.1016/j.indcrop.2015.03.026

Ramos, L., Kristenson, E., \& Brinkman, U. T. (2002). Current use of pressurised liquid extraction and subcritical water extraction in environmental analysis. Journal of Chromatography A, 975(1), 3-29. https://doi.org/10.1016/S0021-9673(02)01336-5

Shi, M., Zhang, Z., \& Yang, Y. (2013). Antioxidant and immunoregulatory activity of Ganoderma lucidum $\begin{array}{llll}\text { polysaccharide (GLP). } & \text { Carbohydrate } & \text { Polymers, } & \text { 95(1), }\end{array}$ https://doi.org/10.1016/j.carbpol.2013.02.081

Sun, H., Wang, S., Li, S., Yuan, X., Ma, J., \& Zhang, Z. (2013). Antioxidant activity and immunomodulatory of extracts from roots of Actinidia kolomikta. International Journal of Biology, 5(3). http://dx.doi.org/10.5539/ijb.v5n3p1 
Wang, C., Chen, Z., Pan, Y., Gao, X., \& Chen, H. (2017). Anti-diabetic effects of Inonotus obliquus polysaccharides-chromium (III) complex in type 2 diabetic mice and its sub-acute toxicity evaluation in normal mice. Food and Chemical Toxicology, in press. https://doi.org/10.1016/j.fct.2017.01.007

Wang, R., Chen, P., Jia, F., Tang, J., \& Ma, F. (2012). Optimization of polysaccharides from Panax japonicus CA Meyer by RSM and its anti-oxidant activity. International Journal of Biological macromolecules, 50(2), 331336. https://doi.org/10.1016/j.ijbiomac.2011.12.023

Wasser, S. (2002). Medicinal mushrooms as a source of antitumor and immunomodulating polysaccharides. Applied Microbiology and Biotechnology, 60(3), 258-274. https://doi.org/10.1007/s00253-002-1076-7

Xu, Y., Cai, F., Yu, Z., Zhang, L., Li, X., Yang, Y., \& Liu, G. (2016). Optimisation of pressurised water extraction of polysaccharides from blackcurrant and its antioxidant activity. Food Chemistry, 194, 650-658. https://doi.org/10.1016/j.foodchem.2015.08.061

Yang, N.-C., Wu, C.-C., Liu, R. H., Chai, Y.-C., \& Tseng, C. Y. (2016). Comparing the functional components, SOD-like activities, antimutagenicity, and nutrient compositions of Phellinus igniarius and Phellinus linteus mushrooms. Journal of Food and Drug Analysis, 24(2), 343-349. https://doi.org/10.1016/j.jfda.2015.11.007

Ye, C.-L., \& Jiang, C.-J. (2011). Optimization of extraction process of crude polysaccharides from Plantago asiatica L. by response surface methodology. Carbohydrate Polymers, 84(1), 495-502. https://doi.org/10.1016/j.carbpol.2010.12.014

Yuan, J.-F., Zhang, Z.-Q., Fan, Z.-C., \& Yang, J.-X. (2008). Antioxidant effects and cytotoxicity of three purified polysaccharides from Ligusticum chuanxiong Hort. Carbohydrate Polymers, 74(4), 822-827. https://doi.org/10.1016/j.carbpol.2008.04.040

Zhang, D., Li, S., Xiong, Q., Jiang, C., \& Lai, X. (2013). Extraction, characterization and biological activities of polysaccharides from Amomum villosum. Carbohydrate Polymers, 95(1), 114-122. https://doi.org/10.1016/j.carbpol.2013.03.015

Zhang, L., \& Wang, M. (2017). Optimization of deep eutectic solvent-based ultrasound-assisted extraction of polysaccharides from Dioscorea opposita Thunb. International Journal of Biological Macromolecules, 95, 675-681. https://doi.org/10.1016/j.ijbiomac.2016.11.096

Zhang, M., Zhang, L., Cheung, P. C. K., \& Ooi, V. E. C. (2004). Molecular weight and anti-tumor activity of the water-soluble polysaccharides isolated by hot water and ultrasonic treatment from the sclerotia and mycelia of Pleurotus tuber-regium. Carbohydrate Polymers, 56(2), 123-128. https://doi.org/10.1016/j.carbpol. 2004.01.005

Zhang, Y., Wang, H., Wang, P., Ma, C., He, G., \& Rahman, M. R. T. (2016). Optimization of PEG-based extraction of polysaccharides from Dendrobium nobile Lindl. and bioactivity study. International Journal of Biological Macromolecules, 92, 1057-1066. https://doi.org/10.1016/j.ijbiomac.2016.07.034

Zhao, Q., Kennedy, J. F., Wang, X., Yuan, X., Zhao, B., Peng, Y., \& Huang, Y. (2011). Optimization of ultrasonic circulating extraction of polysaccharides from Asparagus officinalis using response surface methodology. International Journal of Biological Macromolecules, 49(2), 181-187. https://doi.org/10.1016/j.ijbiomac. 2011.04.012

Zhu, C.-p., Zhai, X.-c., Li, L.-q., Wu, X.-X., \& Li, B. (2015). Response surface optimization of ultrasound-assisted polysaccharides extraction from pomegranate peel. Food Chemistry, 177, 139-146. https://doi.org/10.1016/ j.foodchem.2015.01.022

Zhu, Y., Li, Q., Mao, G., Zou, Y., Feng, W., Zheng, D., . . Y Yang, J. (2014). Optimization of enzyme-assisted extraction and characterization of polysaccharides from Hericium erinaceus. Carbohydrate Polymers, 101, 606-613. https://doi.org/10.1016/j.carbpol.2013.09.099

\section{Copyrights}

Copyright for this article is retained by the author(s), with first publication rights granted to the journal.

This is an open-access article distributed under the terms and conditions of the Creative Commons Attribution license (http://creativecommons.org/licenses/by/4.0/). 